\title{
DISCUSSION
}

\section{Taylor's slope stability chart for combined effects of horizontal and vertical seismic coefficients}

\author{
P. P. SAHOO*, S. K. SHUKLA† and R. GANESH†
}

\begin{abstract}
Contribution by R. Ganesh
The recent paper by Sahoo \& Shukla (2019) presents a simple and alternative approach for assessing the seismic stability of homogeneous cohesive-frictional soil slopes with the help of Taylor's slope stability chart (Taylor, 1937, 1948). The main contribution of the work reported in the paper under discussion appears to be the incorporation of the influence of vertical seismic forces in the reduction factor approach formulated earlier by Majumdar (1971). The authors' attempt in proposing such an easy-to-use approach is welcomed with appreciation by the discusser. However, some aspects of the authors' approach for determining the factor of safety $(F)$ of slopes need to be discussed for better understanding by the geotechnical community. The present discussion paper considers two important aspects. One relates to the interpretation of the authors' results and the other is regarding the simplifications followed in their approach. The discusser would also like to contribute with respect to the correct interpretation of the authors' results for the determination of the safety factor of slopes. This has been demonstrated by taking one of the working examples reported by the authors in their paper.

In the original paper, the reduction friction factor $m$ was obtained by considering an equivalent unit weight $\gamma_{\mathrm{E}}$, aiming to use stability numbers in Taylor's slope stability chart. With the definition of equivalent unit weight $\gamma_{E}$, the authors have actually converted the given pseudostatic seismic problem into a static one with no external forces except the one given by the equivalent vertical body forces. Thus, the original unit weight $\gamma$ used in the definition of the stability number in the Taylor's slope stability chart must be replaced by an equivalent unit weight $\gamma_{\mathrm{E}}$ in the determination of safety factors. According to the reduction factor approach originally proposed by Majumdar (1971), the unit weight of soil $\gamma$ in the stability number (see Fig. 1 of the original article) is the equivalent unit weight, $\gamma_{\mathrm{E}}$.

Based on the above discussion, the correct application of the authors' approach has been demonstrated herein by considering one of the illustrative examples reported by the authors in their paper as follows. Consider a $10 \mathrm{~m}$ high soil slope with an inclination of $60^{\circ}$ to the horizontal (Fig. 9). The soil has the following properties: total unit weight, $\gamma=16 \mathrm{kN} / \mathrm{m}^{3}$; cohesion, $c=20 \mathrm{kPa}$; angle of internal friction, $\phi=25^{\circ}$.
\end{abstract}

\footnotetext{
* Geotechnical and Geoenvironmental Engineering Research Group, School of Engineering, School of Engineering, Edith Cowan University, Perth, WA, Australia

(Orcid:0000-0002-6788-0415).

$\uparrow$ Geotechnical and Geoenvironmental Engineering Research Group, School of Engineering, School of Engineering, Edith Cowan University, Perth, WA, Australia

(Orcid:0000-0002-4685-5560).

† Formerly Department of Civil Engineering, Indian Institute of Technology Roorkee, Uttarakhand, India.
}

Determine the factor of safety $k_{\mathrm{h}}=0 \cdot 1$ taking into account the effect of vertical seismic acceleration.

Assuming that $k_{\mathrm{v}}=0.5 k_{\mathrm{h}}$, the solution is as follows. From Fig. $7(\mathrm{e}), m \approx 0.788$ for both the vertically downward and upward directions of $k_{\mathrm{v}}$. Therefore, using equation (11), the value of $\phi_{\mathrm{m}}$ can be determined as $\phi_{\mathrm{m}} \approx 20^{\circ}$.

From Taylor's chart (Fig. 1), for slope angle, $i=60^{\circ}$ and $\phi_{\mathrm{m}} \approx 20^{\circ}$. The stability factor can be expressed by replacing the original unit weight $\gamma$ with an equivalent unit weight $\gamma_{\mathrm{E}}$ as given below

$$
\frac{c}{F \gamma_{\mathrm{E}} H}=0 \cdot 114
$$

From equation (7)

$$
F=\frac{c}{(0 \cdot 114) \gamma\left[1 \pm k_{\mathrm{v}}+k_{\mathrm{h}}(l / d)\right] H}
$$

From Fig. 3

$$
\begin{aligned}
& l / d \approx 0.85 \\
& F=\frac{20}{(0.114)(16)(1 \pm 0.05+0.1 \times 0.85)(10)}
\end{aligned}
$$

Considering a vertically upward direction of $k_{\mathrm{v}}$

$$
F=\frac{20}{(0 \cdot 148)(16)(1-0.05+0.1 \times 1 \cdot 3)(10)}=1.059
$$

Considering a vertically downward direction of $k_{\mathrm{v}}$

$$
F=\frac{20}{(0 \cdot 148)(16)(1+0.05+0 \cdot 1 \times 1 \cdot 3)(10)}=0.966
$$

The safety factors of slopes actually vary with respect to the assumption of the direction of seismic forces. The critical direction of vertical acceleration in the present analysed case is found to be acting vertically downwards, as would be expected. If the value of factor of safety of slopes is interpreted correctly, as illustrated in this discussion paper, the simple slope considered in this example with the given soil properties and seismic loadings is actually 'unstable'. However, for the same problem, the authors have reported that the slope will be in an 'apparently stable' condition owing to the incorrect interpretation of their results.

It is further noticed that the reduction friction factor $m$ in the original paper has been determined without considering the effect of soil cohesion in the analysis. It appears that the original problem has been overlooked by the authors because the reduction friction factor $m$ only modifies the contribution of soil friction angle towards the stability of slopes for the given pseudostatic seismic loadings. If the original problem was to be considered as it is (without omitting the contribution of cohesion in the analysis), one would actually end up with two reduction factors - one for reducing the contribution of friction angle and another for reducing the contribution of cohesion towards the stability of slopes. 
These two reduction factors must remain the same for the given problem owing to the consideration of a single factor of safety with respect to the shear strength of the soil. This unique value of the reduction factor for reducing the contribution of the friction angle and cohesion of the soil can be easily obtained by adopting an iterative approach or the graphical approach as reported by Taylor $(1937,1948)$. Such an approach would be expected to give a meaningful interpretation of the results from the Taylor's slope stability chart. Despite this shortcoming, the approach of the authors would be easily expected to give safe estimates of the safety factors of slopes, depending upon the magnitude of the cohesion of soil. If the cohesion of the soil is lower, the factor of safety estimated using the authors' approach is expected to be nearly equivalent to the correct value. However, if the contribution of cohesion towards the stability of slopes becomes higher, as would be expected for larger cohesion of the soil, the values of $F$ obtained using the authors' approach can be expected to be significantly different from the correct values. Nevertheless, the approach devised by the authors could be useful as an alternative approach for the preliminary stability assessment of simple slopes taking into account the influence of pseudostatic seismic forces.

The authors of the paper under discussion are invited to shed some light on the various issues raised here pertaining to their work and to clarify the understanding of the interpretation of the results they have obtained for practical applications.

\section{Authors' reply}

The authors thank the discusser for expressing this opinion on the interpretation of results presented as illustrative examples using the total unit weight, $\gamma$, of soil, and on the assumption of no change in the value of cohesion, $c$, during the earthquake, but there is nothing incorrect about these two aspects, as pointed out in the discussion.

It is important to note that, during the combined horizontal and vertical seismic loadings, the total unit weight, $\gamma$, of the soil is modified to $\gamma_{\mathrm{E}}$, as presented in equation (7). As any change in the value of $\gamma$ results in a corresponding change in the angle of internal friction, $\varphi$, of the soil (Lambe \& Whitman, 1979; Duncan et al., 2014), the analysis has been presented with the derivation of an expression for the modified angle of internal friction, $\phi_{\mathrm{m}}$, of the soil in order to take into account the combined effects of horizontal and vertical seismic loads. In equation (11), it may be noticed that $\phi_{\mathrm{m}}$ is a function of $\phi, \gamma, \gamma_{\mathrm{E}}$ and the geometrical parameters related to the slope. As the seismic loads have been properly considered in the estimation of $\phi_{\mathrm{m}}$, the Taylor's slope stability chart for the $c-\phi$ soil slope, as presented in Fig. 1, may be used for the stability number, reading $\phi$ as $\phi_{\mathrm{m}}$. The consideration of $\gamma_{\mathrm{E}}$ in determining the factor of safety $F$ of the slope using Fig. 1, as presented by the discusser, includes the effect of seismic loads twice, resulting in an unrealistic value of $F$. The calculation carried out by the discusser for the example with horizontal seismic coefficient, $k_{\mathrm{h}}=0 \cdot 1$, by considering $\gamma_{\mathrm{E}}$, gives $F=1.059$ for the upward vertical seismic coefficient $k_{\mathrm{v}}(\uparrow)=0.05$ and $F=0.966$ for the downward vertical seismic coefficient $k_{\mathrm{v}}(\downarrow)=0 \cdot 05$, whereas with consideration of $\gamma$, the calculation as presented in the authors' original paper gives $F=1 \cdot 09$. Thus the factor of safety of the slope with $k_{\mathrm{v}}(\uparrow)$ is greater than the factor of safety with $k_{\mathrm{v}}(\downarrow)$, which is not a correct observation, as experienced and reported by many researchers in the past (Richards \& Shi, 1994; Kramer, 1996; FHWA, 1997; Ling \& Leshchinsky, 1997; Ling et al., 1997; Ling \& Leshchinsky, 1998; Ling, 2001; Huang, 2005; Shukha \& Baker, 2008; Das \& Ramana, 2011; Iskander et al., 2013; Zhao et al., 2017).
It appears that the discusser has followed the statement made by Majumdar (1971) about the use of $\gamma_{\mathrm{E}}$, but no illustrative example was given to justify it. As explained here, with proper justification, the total unit weight $\gamma\left(\right.$ not $\left.\gamma_{E}\right)$ should be used in the expression for Taylor's stability number while calculating the factor of safety, $F$, of the slope. This approach has also been presented by Das \& Ramana (2011) while describing the work of Majumdar (1971), who explained how to use the Taylor's chart (Fig. 1) for determining the factor of safety of the slope under a horizontal seismic loading condition only.

In the authors' paper, cohesion of the slope soil has been assumed to be constant with depth and its value remains unchanged during the earthquake period (see assumption $(d)$ on p. 345) for the total stress analysis as considered in the paper. This assumption of unchanged cohesion during the earthquake is based on the past observations and reports by several researchers (Richards \& Shi, 1994; Das \& Ramana, 2011; Agusti \& Sitar, 2013; Duncan et al., 2014). It should be noted that the factor of safety $F$ in the expression of stability number as presented in Fig. 1 and also the calculated value in the illustrative example in the authors' paper refer to the factor of safety with respect cohesion $F=F_{\mathrm{c}}\left(=c / c_{\mathrm{d}}, c_{\mathrm{d}}\right.$ being the developed/mobilised cohesion) based on full mobilisation of the modified friction angle $\phi_{\mathrm{m}}$. As the discusser suggests, the traditional graphical approach, originally explained by Taylor (1937, 1948), and also reported in the literature later (Lambe \& Whitman, 1969; Das \& Ramana, 2011; Steward et al., 2011), may be used by readers while calculating the value of $F$ based on the shear strength of the soil (equation (1), p. 345), and the same has been explained below for the second illustrative example of the authors' paper.

Referring to the $c-\phi$ soil slope in Fig. 9 (height, $H=10 \mathrm{~m}$; slope angle, $i=60^{\circ}$; total unit weight, $\gamma=16 \mathrm{kN} / \mathrm{m}^{3}$; cohesion, $c=20 \mathrm{kPa}$ and angle of internal friction, $\phi=25^{\circ}$ ), from Fig. 7(e), for $k_{\mathrm{h}}=0.5, k_{\mathrm{v}}=0 \cdot 5 k_{\mathrm{h}}=0.25 \downarrow, m \approx 0.281$.

From equation (11)

$$
m=\frac{\tan \phi_{\mathrm{m}}}{\tan \phi}=0 \cdot 281
$$

or

$$
\begin{aligned}
\phi_{\mathrm{m}} & =\tan ^{-1}[0 \cdot 281(\tan \phi)] \\
& =\tan ^{-1}\left[0.281\left(\tan 25^{\circ}\right)\right] \\
& =\tan ^{-1}(0 \cdot 131)
\end{aligned}
$$

or

$$
\phi_{\mathrm{m}} \approx 7.5^{\circ}
$$

(for downward direction of vertical seismic loading)

Similarly, from Fig. $7(\mathrm{e})$, for $k_{\mathrm{h}}=0 \cdot 5, k_{\mathrm{v}}=0 \cdot 5 k_{\mathrm{h}}=0 \cdot 25 \uparrow$, $m \approx 0$.

From equation (11)

$$
m=\frac{\tan \phi_{\mathrm{m}}}{\tan \phi}=0
$$

or

$$
\begin{aligned}
\phi_{\mathrm{m}} & =\tan ^{-1}[0(\tan \phi)] \\
& =\tan ^{-1}\left[0\left(\tan 25^{\circ}\right)\right] \\
& =\tan ^{-1}(0)
\end{aligned}
$$

or

$$
\phi_{\mathrm{m}} \approx 0^{\circ}
$$

(for upward direction of vertical seismic loading) 
Table 1. Computation of factor of safety with respect to friction and cohesion $\left(\phi_{\mathrm{m}} \approx 7 \cdot 5^{\circ}\right)$

\begin{tabular}{|c|c|c|c|c|c|}
\hline $\begin{array}{l}\text { Assumed developed/mobilised friction angle, } \phi_{\mathrm{d}} \\
\text { (1) }\end{array}$ & $\begin{array}{l}\tan \phi_{\mathrm{d}} \\
(2)\end{array}$ & $\begin{array}{c}F_{\phi}=\frac{\tan \phi_{\mathrm{m}}}{\tan \phi_{\mathrm{d}}} \\
\text { (3) }\end{array}$ & $N_{\mathrm{s}}=\frac{c}{F_{\mathrm{c}} \gamma H}=\frac{c_{\mathrm{d}}}{\gamma H}($ from Fig. 1) & $c_{\mathrm{d}}$ & $\begin{array}{c}F_{\mathrm{c}}=\frac{c}{c_{\mathrm{d}}} \\
(6)\end{array}$ \\
\hline $1 \cdot 5^{\circ}$ & 0.0262 & $5 \cdot 028$ & $0 \cdot 1803$ & $28 \cdot 848$ & 0.693 \\
\hline $2 \cdot 5^{\circ}$ & $0 \cdot 0436$ & $3 \cdot 015$ & $0 \cdot 1745$ & $27 \cdot 920$ & $0 \cdot 716$ \\
\hline $3 \cdot 5^{\circ}$ & $0 \cdot 0611$ & $2 \cdot 152$ & $0 \cdot 1687$ & 26.992 & $0 \cdot 741$ \\
\hline $4 \cdot 5^{\circ}$ & 0.0787 & 1.673 & $0 \cdot 1629$ & $26 \cdot 064$ & 0.767 \\
\hline $5 \cdot 5^{\circ}$ & 0.0963 & $1 \cdot 367$ & $0 \cdot 1571$ & $25 \cdot 136$ & 0.796 \\
\hline $6 \cdot 5^{\circ}$ & $0 \cdot 1139$ & $1 \cdot 155$ & $0 \cdot 1513$ & $24 \cdot 208$ & $0 \cdot 826$ \\
\hline $7 \cdot 5^{\circ}$ & $0 \cdot 1316$ & $1 \cdot 000$ & $0 \cdot 1480$ & $23 \cdot 680$ & $0 \cdot 844$ \\
\hline
\end{tabular}

After the computation of $\phi_{\mathrm{m}}$, for determining the factor of safety $F$ of the slope with respect to strength under combined horizontal and vertical seismic loadings, the step-by-step procedure as explained below with numerical values in Table 1 may be followed.

Step 1. Assume several values of developed/mobilised friction angle, $\phi_{\mathrm{d}}\left(\leq \phi_{\mathrm{m}}\right)$ (see column 1 in Table 1) of the soil.

Step 2. Calculate $\tan \phi_{\mathrm{d}}$ (see column 2).

Step 3. Determine the factor of safety of the slope with respect to friction, $F_{\phi}$, for each assumed value of $\phi_{\mathrm{d}}$ (see column 3 ), as defined below

$$
F_{\phi}=\frac{\tan \phi_{\mathrm{m}}}{\tan \phi_{\mathrm{d}}}
$$

Step 4. For each assumed value of $\phi_{\mathrm{d}}$ with slope angle $i$, from Fig. 1, obtain the value of stability number $\left(N_{\mathrm{s}}=\left[\left(c / F_{\mathrm{c}} \gamma H\right)=\left(c_{\mathrm{d}} / \gamma H\right)\right]\right)$ (see column 4$)$

Step 5. Determine $c_{\mathrm{d}}\left(=N_{\mathrm{s}} \gamma H\right)$ corresponding to each value of $\phi_{\mathrm{d}}$ for the given value of $\gamma$ and $H$ of the slope (see column 5).

Step 6. Compute the factor of safety of the slope with respect to cohesion, $F_{\mathrm{c}}=c / c_{\mathrm{d}}$ (see column 6).

Step 7. Plot the graph of $F_{\mathrm{c}}$ against $F_{\phi}$, on the same scale, using the values given in Table 1, and draw a line bisecting the angle between the axes, as shown in Fig. 12. The dashed part of the curve indicates that the developed/mobilised angle of internal friction, $\phi_{\mathrm{d}}$, cannot exceed the modified angle of internal friction $\phi_{\mathrm{m}}$.

Step 8. In Fig. 12, determine the factor of safety of the slope where the bisecting line intersects the curve, giving $F_{\mathrm{c}}=F_{\phi}=0 \cdot 884$.

Step 9. As $F_{\mathrm{c}}=F_{\phi}$ will give the same factor of safety with respect to strength $F$ (Taylor, 1937, 1948; Steward et al., 2011), $F=F_{\phi}=F_{\mathrm{c}}=0.884$ for $k_{\mathrm{h}}=0.5$ and $k_{\mathrm{v}}=0 \cdot 25(\downarrow)$ if the general practice of estimating factor of safety with respect to strength $F$ is followed. As $\phi_{\mathrm{d}}$ cannot exceed $\phi_{\mathrm{m}}$ in the field situation, $F=F_{\mathrm{c}}=0 \cdot 844$ is the more realistic value. Hence, for the slope considered, the factor of safety with respect to strength, $F$, is controlled by the cohesion of the soil.

It may be noted that the factor of safety with respect to cohesion with full mobilisation of the modified angle of internal friction, $F_{\mathrm{c}}=0.844$ (see section $(b)$ of the illustrative example, p. 351, and also the last row of Table 1) is also obtained here by following the traditional graphical approach, mainly because of the low value of modified angle of internal friction, $\phi_{\mathrm{m}}=7 \cdot 5^{\circ}$. For $k_{\mathrm{h}}=0.5$, $k_{\mathrm{v}}=0 \cdot 5 k_{\mathrm{h}}=0 \cdot 25 \uparrow$, the modified friction angle under combined horizontal and vertical seismic coefficients is obtained as $\phi_{\mathrm{m}} \approx 0^{\circ}$; hence, the factor of safety of the slope with respect to strength, $F$, is controlled by cohesion of the soil only; thus $F=F_{\mathrm{c}}=0.694$ as obtained in the authors' paper (see section (b) of the illustrative example, p. 351). In view of the facts presented here, it may be concluded that, for a low value of modified angle of internal friction, say $\varphi_{\mathrm{m}} \leq 10^{\circ}$, practising

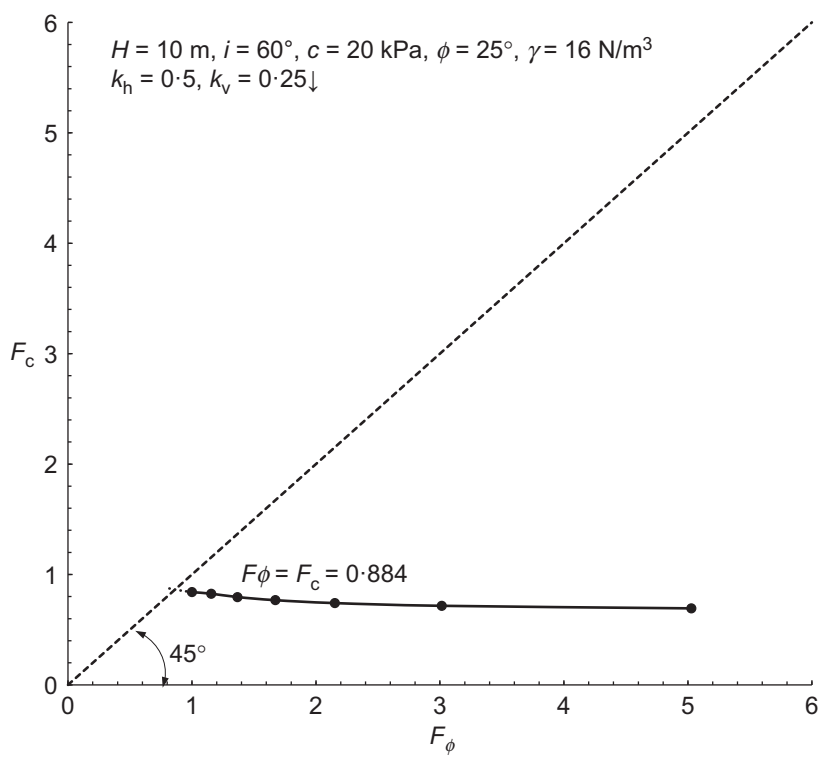

Fig. 12. Variation of $\boldsymbol{F}_{\mathrm{c}}$ against $\boldsymbol{F}_{\phi}$

engineers may avoid the iterative/graphical approach while using the Taylor's slope stability chart for designing the $c-\phi$ soil slope under combined horizontal and vertical seismic loads, for the sake of simplicity, without significant error.

\section{NOTATION}

$c_{\mathrm{d}}$ developed/mobilised cohesion $(\mathrm{kPa})$

$F_{\mathrm{c}}$ factor of safety with respect to cohesion

$F_{\phi}$ factor of safety with respect to friction

$\phi_{\mathrm{d}}$ developed/mobilised angle of internal friction due to generalised earthquake (degrees)

\section{REFERENCES}

Agusti, C. \& Sitar, N. (2013). Seismic earth pressures on retaining structures in cohesive soils, report no. UCB GT 13-02. Berkeley, CA, USA: University of California, Berkeley.

Das, B. M. \& Ramana, G. V. (2011). Principles of soil dynamics. Stamford, CT, USA: Cengage Learning.

Duncan, J. M., Wright, S. G. \& Brandon, L. T. (2014). Soil strength and slope stability. New York, NY, USA: Wiley.

FHWA (Federal Highway Administration) (1997). Geotechnical engineering circular no. 3, design guidance: geotechnical earthquake engineering for highways, vols I and II, publication no. FHWA-SA-97-077. Washington, DC, USA: FHWA.

Huang, C. (2005). Seismic displacements of soil retaining walls situated on slope. J. Geotech. Geoenviron. Engng 131, No. 9, $1108-1117$.

Iskander, M., Chen, Z., Omidvar, M., Guzman, I. \& Elsherif, O. (2013). Active static and seismic earth pressure for $c-\varphi$ soils. Soils Found. 53, No. 5, 639-652. 
Kramer, S. L. (1996). Geotechnical earthquake engineering. Upper Saddle River, NJ, USA: Prentice Hall.

Lambe, T. W. \& Whitman, R. V. (1969). Soil mechanics. New York, NY, USA: Wiley.

Ling, H. I. (2001). Recent applications of sliding block theory to geotechnical design. Soil Dynamics Earthquake Engng 21, No. 3, 189-197.

Ling, H. I. \& Leshchinsky, D. (1997). Seismic stability and permanent displacement of landfill cover systems. Geotech. Geoenviron. Engng 123, No. 2, 113-122.

Ling, H. I. \& Leshchinsky, D. (1998). Effects of vertical acceleration on seismic design of geosynthetic-reinforced soil structures. Géotechnique 48, No. 3, 347-373, https://doi.org/10.1680/geot. 1998.48.3.347.

Ling, H. I., Leshchinsky, D. \& Mohri, Y. (1997). Soil slopes under combined horizontal and vertical seismic accelerations. Earthquake Engng Struct. Dynamics 26, No. 12, 1231-1241.

Majumdar, D. K. (1971). Stability of soil slopes under horizontal earthquake force. Géotechnique 21, No. 1, 84-88, https://doi.org/ 10.1680/geot.1971.21.1.84.
Richards, R. \& Shi, X. (1994). Seismic lateral pressures in soils with cohesion. J. Geotech. Engng, ASCE 120, No. 7, 1230-1251.

Sahoo, P. P. \& Shukla, S. K. (2019). Taylor's slope stability chart for combined effects of horizontal and vertical seismic coefficients. Géotechnique 69, No. 4, 344-354, https://doi.org/10.1680/jgeot. 17.P.222.

Shukha, R. \& Baker, R. (2008). Design implications of the vertical pseudo-static coefficient in slope analysis. Comput. Geotech. 35, No. 1, 86-96.

Steward, T., Sivakugan, N., Shukla, S. K. \& Das, B. M. (2011). Taylor's slope stability charts revisited. Int. J. Geomech. 11, No. 4, 348-352.

Taylor, D. W. (1937). Stability of earth slopes. J. Boston Soc. Civ. Engrs 24, No. 3, 197-246.

Taylor, D. W. (1948). Fundamentals of soil mechanics. New York, NY, USA: Wiley.

Zhao, L., Cheng, X., Dan, H., Tang, Z. \& Zhang, Y. (2017). Effect of the vertical earthquake component on permanent seismic displacement of soil slopes based on the nonlinear MohrCoulomb failure criterion. Soils Found. 57, No. 2, 237-251. 